\title{
LAS MEDIDAS CAUTELARES INNOVATIVAS EN LA NUEVA INSTITUCIONALIDAD MEDIOAMBIENTAL ${ }^{*}$
}

\author{
MAITE AgUiRREZABAL GRÜNSTEIN**
}

RESUMEN: El presente trabajo tiene por objeto efectuar un análisis de los presupuestos necesarios para decretar medidas cautelares innovativas en los procedimientos medioambientales fijados por las Leyes 20.417 y 20.600. Se analizan las similitudes y diferencias existentes entre medida precautoria tradicional y la medida cautelar innovativa, la delimitación de esta última y los requisitos para su otorgamiento en el proceso para la tutela del medio ambiente, con especial énfasis en la configuración del periculum in mora como criterio fundamental para la concesión de la medida. daño.

PALABRAS CLAVE: Medio ambiente - cautela - innovativa - peligro -

\section{INNOVATIVE INJUNCTIONS IN THE NEW ENVIRONMENTAL LEGISLATION}

\begin{abstract}
This paper aims at analyzing the budgets required to grant an innovative injunction in environmental procedures fixed by Laws 20.417 and 20.600. The differences and similarities between the conservative caution and the innovative one, and the delimitation of the latter as well as the requirements for granting the process for the protection of the environment, emphasizing on the concurrence of periculum in mora as a structuring element of the measure are all analyzed along this paper.
\end{abstract}

KEYWORDS: Environment - caution - innovative - danger - damage.

El presente trabajo se elabora en el marco del Proyecto Fondecyt Regular No 1130462, titulado "Recepción y proyección de la medida cautelar innovativa en el sistema procesal chileno", del que la autora es la investigadora responsable.

Fecha de recepción: 4 de marzo de 2015.

Fecha de aceptación: 9 de junio de 2015.

** Doctora en Derecho por la Universidad de Navarra (España), Profesora Investigadora de la Facultad de Derecho de la Universidad de los Andes (CHILE). Correo electrónico:

maguirrezabal@uandes.cl 
Sumario: Introducción. 1) Delimitación de la medida cautelar innovativa. 2) Algunos aspectos del procedimiento para la fijación de medidas cautelares en los procesos medioambientales. (2.1.) Elementos esenciales que configuran el sistema cautelar para la tutela del medio ambiente. (2.2.) Competencia para fijar medidas precautorias en la nueva institucionalidad medioambiental. (2.2.1) Competencia de la Superintendencia para decretar medidas cautelares innovativas en el marco de un procedimiento administrativo. (2.2.2) Competencia de los tribunales ambientales para decretar medidas cautelares innovativas en el marco de un procedimiento jurisdiccional por las infracciones contempladas en la Ley 19.300, sobre bases generales del Medio ambiente. 3) Algunos aspectos del procedimiento seguido ante los tribunales ambientales para la concesión de una medida cautelar innovativa. (3.1.) Iniciativa para su otorgamiento. (3.2.) Acreditación de los requisitos para su concesión. (3.3.) La configuración del periculum in mora como criterio fundamental para decretar una medida cautelar innovativa en el procedimiento medioambiental. (3.3.1.) Una aproximación al concepto de perjuicio irreparable. (3.3.2.) Alcance de la irreparabilidad del perjuicio. (3.3.3.) Excepcionalidad de la medida innovativa. (3.4.) Contracautela. (3.5.) Provisionalidad y bilateralidad en la concesión de la medida. (3.6.) Régimen de Recursos. Conclusiones. Bibliografía citada.

\section{INTRODUCCIÓN}

La protección del medio ambiente se enmarca dentro de los intereses legítimos que en razón de su importancia colectiva se establecen como propios de ciertos grupos o categorías sociales, denominados por la doctrina como intereses supraindividuales o transindividuales ${ }^{1}$.

Obedecen a lo que hoy se categoriza como derechos humanos de tercera generación o derechos de la solidaridad, encontrando su origen científico en la teoría de Karel Vasak, sobre la dimensión internacional de los derechos del hombre.

En ella, junto a la reconocida distinción entre los derechos de primera generación (civiles y políticos) y de segunda generación (económicos y sociales), concibe estos nuevos derechos como aquellos que proceden de una cierta concepción de la vida en comunidad, y solo se pueden realizar

Como expresa Acosta Estévez, José (1995) Tutela procesal de los consumidores. Barcelona: Bosch, p. 40, "estamos en presencia de unos intereses que pertenecen a todos y cada uno de los miembros integrantes de la sociedad. Por tanto, encontramos el reconocimiento de una realidad social: la existencia de unos intereses que precisan protección jurídica y tutela procesal". Se concluye así que las relaciones humanas son decisivas en la aparición de nuevos y distintos intereses en los que aparecen implicados diversos sectores sociales. 
por la conjunción de los esfuerzos de todos los que participan en la vida social $^{2}$.

Hace ya un tiempo que el medio ambiente viene considerándose como un bien jurídico, como una realidad que es objeto de consideración y protección por el Derecho, de tal manera que no basta con su tutela indirecta sino que requiere una tutela autónoma y específica ${ }^{3}$.

Desde la perspectiva del proceso, la tutela jurisdiccional del medio ambiente plantea problemas en su acceso a la justicia, y en este sentido, Mauro Cappelletti, hace ya tres décadas, anticipaba cambios importantes y "oleadas" de reformas en este ámbito, una de las cuales estaba encaminada a asegurar la protección de ciertos derechos e intereses particulares importantes y especialmente vulnerables en las sociedades postindustriales que se basan en la masificación de la producción, de la distribución y del consumo ${ }^{4}$.

Esta nueva realidad conlleva entonces la búsqueda de una efectiva defensa que exige soluciones distintas, más rápidas y eficientes, lo que en opinión de Morello lleva a "otro modo de pensar y actuar del derecho instrumental, facilitador de la protección útil de los mismos" 5 , y que requiere "articular vías y procedimientos no menos singulares, apropiados para la tutela diferenciada de los derechos en juego, en los que se involucran las responsabilidades de las partes, los poderes y deberes de iniciativa y de

2 VASAK, Karel (1982) "Human rights: as a legal reality". The international dimensions of human rights. Connecticut: Greenwood Press, pp. 3-10. En este sentido también BerTelsen, Repetto, Raúl (1998) "El recurso de protección y el derecho a vivir en un medio ambiente libre de contaminación. Examen de quince ańos de jurisprudencia”. Revista Chilena de Derecho, Vol. 25, No 1, pp. 139-174.

3 Gutiérrez De Cabiedes, Pablo (1998) La tutela jurisdiccional de los intereses supraindividuales; colectivos y difusos. Navarra: Aranzadi, p. 344; Aguirrezabal Grünstein, Maite (2006) "Algunas precisiones en torno a los intereses supraindividuales: colectivos y difusos". Revista Chilena de Derecho, Vol. 33 N$^{\circ}$ 1, pp. 69 - 91 y (2014) Defensa de los consumidores y acceso a la justicia. Un análisis del proceso colectivo en la legislación chilena. Santiago: Editorial Legal Publishing; Bordalí Salamanca, Andrés (2004) La tutela jurisdiccional del medio ambiente. Santiago: Editorial Fallos del Mes; y (1998) "Titularidad y legitimación activa sobre el ambiente en el Derecho chileno". Revista de Derecho, Universidad Austral de Chile, Vol. IX, diciembre, pp. 43-64; Palomo Vélez, Diego (2003) "Tutela del medio ambiente: abandono del paradigma de la litis individual". Revista de Derecho de la Universidad Austral de Chile, Vol. XIV, pp. 187-201 y Moscoso Restovic, Pía (2011) "Principios de competencia judicial internacional y de protección del medio ambiente". Ius et Praxis, Vol. 17, $\mathrm{N}^{\circ}$ 2, pp. 283-304.

4 Cappelletti, Mauro (1995) "Formaciones sociales e intereses de grupo frente a la justicia civil”. Boletín Mexicano de Derecho Comparado, N 83, pp. 1-40. En este mismo sentido, Morello, Augusto (1998) Estudios de derecho procesal: nuevas demandas, nuevas respuestas. Buenos Aires: Abeledo-Perrot, p. 1083, quien señala que estos intereses de nuevo cuño motivan y exigen soluciones jurídicas distintas a las tradicionales, "otro modo de pensar y actuar el derecho instrumental, facilitador de la protección útil de los mismos". Morello (1998) 1083. 
control del juez y los efectos mismos de las decisiones por el alcance particular de la cosa juzgada"6.

Es también una realidad objetiva y no menos trascendental, que entre el inicio de la relación procesal y el cumplimiento de la sentencia definitiva, pueden ocurrir varias alteraciones jurídicas o de hecho, que terminen frustrando la pretensión del actor, y la falta de eficacia que se constata en la utilización de los diversos procedimientos, ha intentado solucionarse buscando distintas fórmulas, que tienen como objetivo común enfrentar la demora del proceso.

La legislación chilena no ha estado ajena a los conflictos planteados, y en orden a cumplir con los requerimientos nacionales e internacionales, especialmente con el ingreso de Chile a la $\mathrm{OCDE}^{7}$, la institucionalidad medioambiental ha sufrido una serie de reformas, principalmente a través de la Ley 20.417, de 26 de enero de 2010, Orgánica de la Superintendencia del Medio Ambiente y de la Ley 20.600, de 28 de junio de 2012, que crea los tribunales ambientales y fija un procedimiento especial para la resolución de los conflictos que se produzcan por infracciones a la Ley 19.300 ${ }^{8}$, sobre Bases Generales del Medio Ambiente.

Ambos cuerpos normativos crearon instituciones que sirven de marco al modelo de protección medioambiental, tales como el Ministerio del Medio Ambiente, el Servicio de Evaluación de Impacto Ambiental y la Superintendencia del Medio Ambiente, reformando además la Ley 19.300, especialmente en lo que se refiere al sistema de evaluación del impacto ambiental.

A los Tribunales Ambientales, órgano jurisdiccional especial encargado de resolver los conflictos ambientales 9 , la Ley 19.300 les entrega la "competencia para conocer las causas que se promuevan por infracción a

6 Berizonce, Roberto (2003) "Presentación del libro La tutela de los derechos difusos, colectivos e individuales homogéneos". En Gidi, Antonio y Ferrer Mac-Gregor, Eduardo (coordinadores): Hacia un Código Modelo para Iberoamérica. México: Editorial Porrúa, pp. XV-XVI.

$7 \quad$ La OCDE ha estimado que los desafíos ambientales de Chile, son principalmente: i) aplicar sus políticas ambientales de forma cabal y eficiente; ii) profundizar en la integración de las consideraciones ambientales en las decisiones económicas, sociales y sectoriales; y iii) fortalecer su cooperación ambiental internacional. Las Evaluaciones del desempeño ambiental efectuadas por la OCDE se encuentran disponibles en: www.sinia.cl/1302/articles-57009_ EDA2005_OCDE_CEPAL.pdf [fecha de visita: 21 de diciembre de 2014].

8 Hasta la publicación de la ley en comento, el procedimiento aplicable era el juicio sumario con las especialidades establecidas en la Ley de Bases Generales del Medio Ambiente (Ley 19.300).

9 Y que el artículo $1^{\circ}$ de la Ley 20.600 define como órganos jurisdiccionales especiales, sujetos a la superintendencia directiva, correccional y económica de la Corte Suprema, cuya función es resolver las controversias medioambientales de su competencia y ocuparse de los demás asuntos que la ley somete a su conocimiento. 
la presente ley, el Tribunal Ambiental, de conformidad a las normas de procedimiento establecidas en la ley que lo crea" ${ }^{10}$.

\section{1) DELIMITACIÓN DE LA MEDIDA CAUTELAR INNOVATIVA}

Con el reconocimiento que la doctrina y la jurisprudencia paulatinamente han efectuado de nuevas formas de tutela cautelar, se ha superado el carácter tradicionalmente conservativo asignado a las medidas precautorias, configurando nuevos instrumentos, como las medidas innovativas y las medidas autosatisfactivas ${ }^{11}$.

Las medidas cautelares innovativas, pueden conceptuarse como "aquellas que tienden a obtener una providencia no contemplada en previsiones legislativas específicas (sin perjuicio de la regulación que pueda hacer el legislador en determinados casos), otorgando en forma anticipada total o parcialmente el objeto mediato de la pretensión contenida en la demanda" ${ }^{12}$, y que según la naturaleza del interés, la inminencia o presencia efectiva de un perjuicio irreparable o de difícil reparación, o las particulares circunstancias que surgen de la situación jurídica, la decreta el juez para obviar las consecuencias perjudiciales de un evento que podría producir la supresión o la restricción de los efectos obligatorios o ejecutivos de la decisión sobre el fondo.

La protección consiste precisamente en una decisión anticipada sobre el asunto controvertido, destinada a durar hasta el momento en que a esta regulación provisoria se sobreponga la regulación de carácter estable que se puede conseguir a través de la sentencia definitiva ${ }^{13}$.

No constituyen un fin por sí mismas, sino que están ineludiblemente preordenadas a la emanación de una ulterior providencia definitiva y al

$10 \quad$ Artículo 60 de la Ley 19.300.

11 Entre la abundante bibliografía, con las tendencias producidas en el derecho comparado, Comoglio, Luigi y Ferri, Corrado (1990) "La tutela cautelare in Italia". Rivista di Diritto Processuale. Padova: Cedam, T. XLV, pp. 963-972; Gascón Inchausti, Fernando (1998) Medidas cautelares de proceso civil extranjero. Granada: Comares, pp. 65-165; Baptista DA Silva, Ovidio (1993) Teoría de la acción cautelar. Porto Alegre: Fabris Editor, pp. 9-127; Berizonce, Roberto (1996) "La tutela cautelar y la prestación jurisdiccional efectiva”. Revista Uruguaya de Derecho Procesal, N¹, pp. 24-26; Vescovi, Enrique (1996) "La búsqueda de una mayor eficacia para la justicia. Ejecución. Tutela anticipada y otras medidas en el Derecho comparado". Revista Uruguaya de Derecho Procesal, № 3, pp. 183-191. En nuestra doctrina es obligatoria la consulta del trabajo de Marín González, Juan Carlos (2004) Las medidas cautelares en el proceso civil chileno. Santiago: Editorial Jurídica de Chile.

12 Carbone, Carlos (2009) "Esquicio diferenciador entre la medida cautelar innovativa y el despacho interino de fondo". En Peyrano, Jorge (Director): Medida Innovativa. Buenos Aires: Rubinzal-Culzoni, pp. 83-106, p. 85.

13 Calamandrei, Piero (2006) Introducción al Estudio Sistemático de las Medidas Cautelares. Lima: Ara Ediciones, pp. 58-59. 
resultado práctico que aseguran preventivamente ${ }^{14}$, continuando el proceso hasta la dictación de la sentencia definitiva, que puede pronunciarse incluso en un sentido distinto del criterio utilizado para el otorgamiento anticipado de la tutela.

A pesar de que el tratamiento de estas nuevas formas de tutela judicial es incipiente, la discusión en torno a la naturaleza jurídica y los fines que persiguen lleva ya bastante tiempo asentada en la doctrina.

Calamandrei ya había advertido que ciertos supuestos de peligro en la tardanza podían frustrar la satisfacción del derecho, casos en los que sería necesario acelerar provisoriamente la solución.

En su ya tradicional clasificación de las medidas cautelares, señalaba que las providencias de este tipo pueden asumir diversas formas, pudiendo clasificarse en cuatro tipos: las providencias instructoras anticipadas, relativas a la conservación de medios probatorios; las providencias de aseguramiento de la futura ejecución forzada, equivalente a las medidas de carácter asegurativo; las decisiones anticipadas y provisorias de mérito y las providencias que imponen cauciones judiciales.

Estas últimas serían aquellas que "deciden interinamente, antes de la decisión definitiva, una relación controversial que de no hacerse podrían derivar en daños irreparables" 15 .

$\mathrm{Su}$ objeto es que "alguien haga o deje de hacer algo en sentido contrario al representado por la situación existente" 16 , lo que se traduce en la injerencia del tribunal en la esfera de libertad de los justiciables a través de la orden de que cese una actividad contraria a derecho o de que se retrotraigan las resultas consumadas de un proceder antijurídico sin que concurra sentencia firme.

A lo anterior debe sumarse la contribución que Carnellutti efectúa a esta discusión, puesto que en sus últimos trabajos sobre la materia, dividió los procesos cautelares en inhibitorios, restitutorios y anticipatorios, reconociendo por lo tanto que la medida cautelar no solo tiene por objeto una finalidad meramente asegurativa de bienes ${ }^{17}$, ya que en ciertas ocasiones "de lo que se trata no es de eliminar una peligrosa desigualdad entre los litigantes, sino de anticipar proveimientos que, si recayesen en el momento normal, perderían en todo o en parte su eficacia" ${ }^{18}$.

14 Calamandrei (2006) 44-45. Más que a hacer justicia contribuyen a garantizar el eficaz funcionamiento de la justicia

15 Calamandrei (2006) 53.

16 Peyrano, Jorge (2009) "La medida cautelar innovativa: una realidad, una esperanza". En Peyrano, Jorge (Director): Medida Innovativa. Buenos Aires: Rubinzal-Culzoni, pp. 213234.

17 Carnellutti, Francesco (1944) Sistema de Derecho Procesal Civil, trad. Alcalá-Zamora. Buenos Aires: UTEHA, pp. 246-248.

18 Carnellutti (1944) 250. 
La cautela innovativa exige al órgano jurisdiccional una conducta activa que vaya más allá de la orden de abstención de realizar ciertos actos o conductas, imponiéndole una obligación de hacer o dejar de hacer algo pero en sentido contrario al que existía con anterioridad a decretarse dicha medida.

La proyección de sus efectos "trasciende la mera provisionalidad, por cuanto constituye una concreta satisfacción de los derechos pretendidos por el solicitante que, aunque puede hacerse cesar, habrán sido gozados irrevocablemente" 19 y en consecuencia, se caracteriza por ordenar, sin que exista sentencia firme, que se haga o se deje de hacer algo en sentido contrario al representado por la situación existente ${ }^{20}$.

La medida innovativa se distingue también de la medida conservativa en lo que respectan a la finalidad que persiguen.

Mediante los mecanismos clásicos de tutela cautelar se busca conservar o inmovilizar una situación de hecho, para impedir los cambios de la misma que pudieran frustrar después el resultado práctico del proceso principal, es decir, evitar que se frustre la ejecución de la sentencia.

Mientras que la medida cautelar innovativa se presenta entonces como una modificación anticipada de una situación jurídica ${ }^{21}$ con el objeto de evitar un perjuicio irreparable a alguna de las partes, la medida cautelar en su concepción tradicional está llamada a conservar, a no innovar respecto de esa situación ${ }^{22}$, constituyendo su finalidad la de impedir la alteración de una situación de hecho o la destrucción de un bien.

Ambos tipos de medida coinciden en el hecho de estar preordenadas a una sentencia de fondo ${ }^{23}$, impidiendo que se lleve a cabo una determinada actuación, o bien ordenando que dicha actuación se practique, pero además, la medida innovativa se encuentra orientada a evitar que se produzca un perjuicio que adquiera el carácter de irreparable con el transcur-

19 Garrote, Angel (1997) "La tutela judicial anticipada. Las medidas de satisfacción anticipada y las medidas autosatisfactivas". Libro de Ponencias del XIX Congreso Nacional de Derecho Procesal, Corrientes, 6 al 8 de agosto de 1997, p. 78.

20 Así lo explica, Minvielle, Bernardette (1995) "La problemática de la medida cautelar innovativa”. Revista Uruguaya de Derecho Procesal, No 2, p. 362.

21 Peyrano, Jorge (1981) Medida Cautelar Innovativa. Buenos Aires: Depalma.

22 La misma situación se presenta a propósito del recurso de protección, puesto que a pesar de tratarse de un procedimiento reconocido ampliamente como de urgencia, se limita a ordenar que provisionalmente se suspendan los efectos del acto supuestamente lesivo, pero no a la modificación o alteración de los mismos. Sobre este punto en particular, vid. BordaLI Salamanca, Andrés (2006) "El recurso de protección entre exigencias de urgencia y seguridad jurídica”. Revista de Derecho de la Universidad Austral de Chile, diciembre, Vol. 19, N 2, pp. 205-228.

23 Lo que las diferencia a ambas de la medida autosatisfactiva. 
so del proceso, de tal manera que la adopción de una medida de este tipo evita que dicha irreparabilidad se produzca ${ }^{24}$.

Por la razón anterior, la medida innovativa es siempre excepcional ${ }^{25}$, y para que se persiga alterar la situación existente, requiere no solo de la concurrencia de los requisitos propios de toda medida cautelar, esto es, verosimilitud del derecho y peligro en la demora sino que se exige también un requisito específico para este tipo de medidas: la posibilidad de que se consume un perjuicio irreparable.

Como correctamente señala Arazi, la cautela de conservación sirve para garantizar los medios del proceso definitivo, mientras que la cautela innovativa sirve para garantizar la practicidad del proceso definitivo ${ }^{26}$.

\section{2) Algunos aspectos DEL PROCEDIMIENTO PARA LA FiJACión de MEDIDAS CAUTELARES EN LOS PROCESOS MEDIOAMBIENTALES}

\section{(2.1.) ELEMENTOS ESENCIALES QUE CONFIGURAN EL SISTEMA CAUTELAR PARA LA TUTELA DEL MEDIO AMBIENTE}

La protección del medio ambiente en el ámbito jurisdiccional se refleja en la de una tutela que se sustenta principalmente en el principio preventivo, en virtud del cual el dańo medioambiental debe ser evitado o minimizado mediante medidas entre las que destacan las de tipo caute$\operatorname{lar}^{27}$

Por ello es que nuestra actual legislación no solo se preocupa de tutelar el interés una vez que el dańo se ha consumado y debe repararse, sino que también incorpora esta protección para cuando el daño es inminente o existe peligro o riesgo fundado de que este pudiera producirse.

Siguiendo esa orientación, nuestra actual normativa establece la posibilidad de adoptar medidas cautelares de carácter conservativo o innovativo, colocando dicha actividad en manos de la Superintendencia del Medio Ambiente y de los Tribunales Ambientales.

\footnotetext{
24 Las medidas de esta clase aspiran a evitar — directa o indirectamente - que desaparezcan bienes de dominio del deudor, que en definitiva frustren el cumplimiento de la sentencia judicial a que da lugar la admisión de la acción.

25 Ello porque la medida implica la injerencia del juez en la esfera de libertad del justiciable. Peyrano (1981) 13; y en ponencia (2005) "Sobre usos equivocados de la prohibición innovar y de la medida innovativa”. Derecho Procesal, III Congreso Internacional. Lima: Universidad de Lima, pp. 247-255. Otros aportes sobre el tema, De Los SAntos, Mabel (1995) "La medida cautelar innovativa y el anticipo de la sentencia. Su ubicación en los llamados procesos urgentes". Revista Uruguaya de Derecho Procesal, N², pp. 165-169.

26 Arazi, Roland (2005) "Procesos Urgentes". Justicia Argentina I, p. 1348.

27 Sobre los elementos para diferenciar el principio preventivo y el principio precautorio, Lloret, Elsa (2011) "El principio preventivo y precautorio en el derecho ambiental. ¿A qué principio responde la evaluación de impacto ambiental?”. Ponencia presentada para las Primeras Jornadas Internacionales sobre Sociedad, Estado y Universidad, Mar del Plata.
} 
Debe distinguirse la potestad que posee la Superintendencia del Medio Ambiente para dictar medidas cautelares en el marco de un procedimiento administrativo sancionatorio, y aquella que posee el Tribunal Ambiental para adoptar estas cautelas en el marco de la tramitación de un procedimiento jurisdiccional incoado por los daños contemplados en la ley 19.300, lo que además es sin perjuicio de que en ciertos supuestos, la ley haya también previsto la actuación complementaria de ambas entidades, como se analizará en el siguiente apartado.

\section{(2.2.) COMPETENCIA PARA FIJAR MEDIDAS PRECAUTORIAS EN LA NUEVA INSTITUCIONALIDAD MEDIOAMBIENTAL}

\section{(2.2.1.) Competencia de la Superintendencia para decretar medidas cautelares innovativas en el marco de un procedimiento administrativo}

La Superintendencia, como órgano encargado de la "fiscalización del permanente cumplimiento de las normas y condiciones sobre la base de las cuales se han aprobado o aceptado los estudios y declaraciones de impacto ambiental..." 28 , se encuentra legalmente facultada según dispone el artículo $3^{\circ}$ de la ley 20.417, para adoptar medidas de importante entidad, tales como: a) Suspender transitoriamente las autorizaciones de funcionamiento contenidas en las Resoluciones de Calificación Ambiental o adoptar otras medidas urgentes y transitorias para el resguardo del medio ambiente, cuando la ejecución u operación de un proyecto o actividad genere un dańo grave e inminente para el medio ambiente, a consecuencia del incumplimiento grave de las normas, medidas y condiciones previstas en dichas resoluciones; b) Suspender transitoriamente las autorizaciones de funcionamiento contenidas en las Resoluciones de Calificación Ambiental o adoptar otras medidas urgentes y transitorias, para el resguardo del medio ambiente, cuando la ejecución u operación de los proyectos o actividades, genere efectos no previstos en la evaluación y como consecuencia de ello se pueda generar un dańo inminente y grave para el medio ambiente y c) Imponer sanciones de conformidad a lo señalado en la Ley $20.417^{29}$.

Estas facultades deben concordarse con lo dispuesto por los artículos 47 y siguientes de la citada ley, que establecen el procedimiento para la

\footnotetext{
28 Artículo 64 de la ley 19.300, que agrega además, de las medidas e instrumentos que establezcan los planes de prevención y de descontaminación, de las normas de calidad y emisión, así como de los diversos planes de manejos".

29 Facultades que se encuentran consagradas respectivamente en el artículo $3^{\circ}$ letras g), h) y o) de la ley 20.417.
} 
aplicación de sanciones por parte de la Superintendencia, y que le permiten decretar medidas cautelares de carácter innovativo ${ }^{30}$.

En este sentido, el artículo 48 del texto legal establece que cuando se haya iniciado el procedimiento sancionador, el instructor, con el objeto de evitar un dańo inminente al medio ambiente o a la salud de las personas, podrá solicitar fundadamente al Superintendente la adopción de alguna o algunas de las siguientes medidas provisionales: a) Medidas de corrección, seguridad o control que impidan la continuidad en la producción del riesgo o del daño; b) Sellado de aparatos o equipos; c) Clausura temporal, parcial o total, de las instalaciones; d) Detención del funcionamiento de las instalaciones; e) Suspensión temporal de la resolución de calificación ambiental; f) Ordenar programas de monitoreo y análisis específicos que serán de cargo del infractor.

La norma reseñada constituye una novedad en lo que respecta a los mecanismos de tutela cautelar, aunque encontramos un antecedente directo en la Ley $\mathrm{N}^{\circ} 19.880$ de 2003 , que establece las bases de los procedimientos administrativos.

Dicha ley, en su artículo 32, ya reconocía al órgano administrativo la posibilidad de adoptar medidas provisionales, una vez que se hubiera iniciado el procedimiento, pudiendo decretar de oficio o a petición de parte, las medidas provisionales que estimara oportunas "para asegurar la eficacia de la decisión...", pudiendo adoptarse incluso antes de la iniciación del procedimiento administrativo, "en los casos de urgencia y para la protección provisional de los intereses implicados...", incorporando de modo general la cautela innovativa en el procedimiento administrativo ${ }^{31}$.

La legislación medioambiental actual se separa de la orientación adoptada por la Ley 19.880 en el sentido que restringe el ámbito de aplicación de la cautela innovativa, ya que dispone que las medida decretadas antes de que se haya iniciado el procedimiento sancionatorio solo pueden tener fines cautelares, debiendo además ser proporcionales al tipo de infracción cometida y a las circunstancias que señala el artículo 40 de la Ley $20.417^{32}$.

30 Sobre la evolución de la competencia de la Administración en esta material resulta relevante el trabajo de Bermúdez Soto, Jorge (2013) "Fundamento y límites de la potestad sancionadora administrativa en materia ambiental". Revista de Derecho de la Pontificia Universidad Católica de Valparaíso, N 40, pp. 421-447.

31 Estas medidas provisionales deberán ser confirmadas, modificadas o levantadas en la iniciación del procedimiento, que deberá efectuarse dentro de los quince días siguientes a su adopción.

32 Y que establece que para la determinación de las sanciones específicas que en cada caso corresponda aplicar, se considerarán las siguientes circunstancias:

a) La importancia del dańo causado o del peligro ocasionado.

b) El número de personas cuya salud pudo afectarse por la infracción.

c) El beneficio económico obtenido con motivo de la infracción. 
No contempla tampoco, a diferencia de lo que sucede con la Ley de Bases de Procedimientos Administrativos, una norma relativa a la prohibición de causar perjuicio a la contraparte con la adopción de la medi$\mathrm{da}^{33}$, aunque creemos que atendidos los principios informativos de estas nuevas modalidades de tutela, su inclusión habría sido recomendable ${ }^{34}$.

Lo que sí establece la norma es un requisito de temporalidad, propio de toda medida cautelar, ya que la vigencia de estas medidas será de 30 días corridos, pudiendo renovarse dicho período mediante resolución fundada 35 .

La ley ha implementado también una actuación coordinada de la Superintendencia y de los tribunales ambientales, en los casos en que se decreten algunas de las medidas previstas en las letras c), d) y e) del artículo 48, esto es, la clausura temporal, la detención del funcionamiento de las instalaciones, la suspensión temporal de la resolución de calificación ambiental o las suspensiones de las letras g) y h) del artículo $3^{\circ}$ del mismo texto legal ${ }^{36}$.

Para estas hipótesis específicas, el legislador ha exigido que la medida decretada por la Superintendencia deba contar con la autorización del Tribunal Ambiental.

d) La intencionalidad en la comisión de la infracción y el grado de participación en el hecho, acción u omisión constitutiva de la misma.

e) La conducta anterior del infractor.

f) La capacidad económica del infractor.

g) El cumplimiento del programa seńalado en la letra r) del artículo $3^{\circ}$.

h) El detrimento o vulneración de un área silvestre protegida del Estado.

i) Todo otro criterio que, a juicio fundado de la Superintendencia, sea relevante para la determinación de la sanción.

33 Así el artículo 32 de la Ley 19.880, en su inciso $4^{\circ}$, establece que "no se podrán adoptar medidas provisionales que puedan causar perjuicio de dificil o imposible reparación a los interesados, o que impliquen violación de derechos amparados por las leyes".

34 Sobre el particular, Menéndez, Patricia (2009) "La medida innovativa como herramienta para afianzar la justicia”. En Peyrano, Jorge (Director): Medida Innovativa. Buenos Aires: Rubinzal-Culzoni, pp. 389-417, pp. 389-390 y Balestro Faure, Miryam (2009) "La medida innovativa: ¿cuándo, cómo y para qué? En Peyrano, Jorge (Director): Medida Innovativa. Buenos Aires: Rubinzal-Culzoni, pp. 371-388.

35 La ley no ha establecido el número de veces que podrá renovarse la medida.

36 Dichas suspensiones se refieren a autorizaciones de funcionamiento contenidas en las Resoluciones de Calificación Ambiental. Debe hacerse presente que la autorización del Tribunal Ambiental solo alcanzaría las medidas de suspensión y no las medidas urgentes y transitorias, para las que el legislador no ha previsto dicha autorización. En este sentido, Silva Montes, Rodrigo. Informe en Derecho de fecha 15 de julio de 2013, disponible en: www. tribunalambiental.cl/2ta/wp-content/uploads/2014/07/R-06-2013-Informe-en-derecho-dedon-Rodrigo-Silva-Montes.pdf, [fecha de visita: 4 de enero de 2015] y Bermúdez Soto, Jorge (2013) "Régimen de ejecutoriedad de las resoluciones de calificación ambiental y de las medidas urgentes y transitorias del art. 3 G) LOSMA", Informe en Derecho de julio de 2013, disponible en: www.tribunalambiental.cl/2ta/wp-content/uploads/2014/07/R06-2013-Informe-en-derecho-de-don-Jorge-Bermudez-Soto.pdf [fecha de visita: 4 de enero de 2015]. Ambos acompañados a los autos R-6-2013, caratulados "Reclamación de Rubén Cruz Pérez y otros contra la Superintendencia del Medio Ambiente”. 
Se ha entendido por nuestra jurisprudencia que esta exigencia se enmarca dentro del principio de control judicial de los actos de la administración "como garantía en favor del presunto infractor o interesado afectado, para evitar que el titular del proyecto sea sometido a medidas de considerable entidad, sin un control jurisdiccional previo" 37 , constituyendo este requisito un mecanismo de revisión y control de las actuaciones de la Superintendencia en esta materia.

Por lo mismo, la Ley ha previsto mecanismos ágiles para su consecución, ya que la autorización podrá incluso obtenerse por vía telefónica ${ }^{38}$, siendo competente para concederla el tribunal del lugar en que la medida vaya a ser ejecutada ${ }^{39}$.

La autorización en comento no es exigible si la Superintendencia decreta alguna de las medidas que el artículo $3^{\circ}$ ha previsto como "urgentes y transitorias", y que se han caracterizado como aquellas que permitirían seguir realizando por parte del órgano administrativo una serie de seguimientos de variables ambientales ${ }^{40}$, a diferencia de lo que sucede con la suspensión, paralización o clausura, que impediría cualquier actuación posterior a su decreto.

\section{(2.2.2.) Competencia de los tribunales ambientales para decretar medidas cautelares innovativas en el marco de un procedimiento jurisdiccional por las infracciones contempladas en la Ley 19.300, sobre Bases Generales del Medioambiente}

Tal como ya se señaló, el artículo 60 de la Ley 19.300 entrega al Tribunal Ambiental la competencia para conocer de las infracciones a dicha

37 Considerando centésimo trigésimo octavo de la sentencia de fecha 3 de marzo de 2014, pronunciada en la causa por reclamación rol n $\mathrm{R}$ 6-2013, caratulada "Agricultores y regantes de la comuna de Alto del Carmen y las Comunidades Indígenas Diaguitas c. Agrícola Santa Mónica Limitada y Dos Hermanos Limitada”, seguida ante el Segundo Tribunal Ambiental.

38 Establece el artículo 48 en el inciso $4^{\circ}$ que se entregará al propietario o encargado un certificado que indique la medida adoptada, la individualización del instructor del procedimiento y de aquel juez que lo hubiere ordenado, dejando copia de dicho certificado en el expediente sancionatorio. Sobre las relaciones entre el sistema cautelar administrativo y jurisdiccional y el control que el Tribunal Ambiental ejerce sobre la Superintendencia, Romero SEguel, Alejandro, "Informe en Derecho. Distinción entre el sistema cautelar administrativo y jurisdiccional", disponible en: http://ribunalambiental.cl/2ta/wp-content/uploads/2013/09/R06-2013-02-09-2013-Compa\%C3\%B1\%C3\%ADa-Minera-Nevada-SpA-2.pdf [fecha de visita: 4 de enero de 2015].

39 Altera la norma la regla general en cuanto a la competencia relativa de los tribunales.

40 Así lo ha defendido la Superintendencia del Medio Ambiente en la causa por reclamación rol n ${ }^{\circ}$ R 6-2013, "Agricultores y regantes de la comuna de Alto del Carmen y las Comunidades Indígenas Diaguitas c. Agrícola Santa Mónica Limitada y Dos Hermanos Limitada”, seguida ante el Segundo Tribunal Ambiental, a propósito de la distinción entre decretar la paralización o la suspensión de una determinada actividad. 
normativa, con el procedimiento que contempla la Ley 20.600, lo que se encuentra además en concordancia con lo dispuesto por el artículo $17 \mathrm{n}^{\circ}$ 2 de la misma ley ${ }^{41}$.

De esta manera, y de acuerdo con las normas de procedimiento fijadas por la Ley 20.600, el Tribunal Ambiental también se encuentra facultado para adoptar medidas cautelares dentro de un proceso jurisdiccional del que se encuentre actualmente conociendo.

El artículo 24 de la ley se encarga de regular las medidas cautelares, definiendo las medidas conservativas como "aquellas que tengan por objeto asegurar el resultado de la pretensión, a través de acciones destinadas a mantener el estado de hecho o de derecho existente con anterioridad a la solicitud de la medida", y como medidas innovativas "aquellas que, con el mismo objeto, buscan modificar el estado de hecho o de derecho existente al tiempo de la solicitud de la medida" 42 .

\section{3) Algunos ASPECTOS DEL PROCEDIMIENTO SEgUIDO ANTE LOS Tribunales AMbientales PARA LA CONCESIÓN DE UNA MEDIDA CAUTELAR INNOVATIVA}

\section{(3.1.) INICIATIVA PARA SU OTORGAMIENTO}

En lo que respecta al procedimiento, el Tribunal Ambiental que se encuentre conociendo de un asunto de su competencia, podrá decretar estas medidas de oficio o a petición de parte, en cualquier estado del proceso, e incluso antes de su inicio por el plazo que estime conveniente ${ }^{43}$.

Si la medida precautoria se hubiere concedido prejudicialmente el solicitante deberá presentar su demanda en el plazo de quince días hábiles contado desde que se concedió la cautela o en el término mayor que fije el Tribunal. Si así no lo hiciere la medida quedará sin efecto de pleno derecho.

Si es la parte la que solicita la medida, el tribunal deberá decretarla mediante resolución fundada, de plano o con citación ${ }^{44}$.

41 Y que dispone que para conocer de las demandas para obtener la reparación del medio ambiente dañado, en conformidad con lo dispuesto en el Título III de la Ley No 19.300 será competente para conocer de estos asuntos el Tribunal Ambiental del lugar en que se haya originado el hecho que causa el dańo, o el de cualquier lugar en que el daño se haya producido, a elección del afectado".

42 Orientándose por criterio tradicionales en cuanto a la definición, ya asentado en nuestra jurisprudencia, especialmente en el área de los Tribunales de Familia.

43 Repite la facultad ya contenida en la Ley de Procedimiento I Administrativo y en la Ley 20.417, pero en este caso no existe la limitación temporal ni de contenido que el legislador ha fijado para el evento que la medida la adopte la Superintendencia. Entendemos que en el caso de decretarse la medida de modo prejudicial, opera exclusivamente el principio dispositivo en su solicitud.

44 Lo que implica que el legislador ha negado la tramitación incidental ab initio de la medida cautelar, pudiendo trabarse ese incidente solo en el caso que la contraparte haga uso del 


\section{(3.2.) ACREDITACIÓN DE LOS REQUISITOS PARA SU CONCESIÓN}

El sistema cautelar descansa básicamente en dos elementos esenciales: el fumus boni iuris y el periculum in mora ${ }^{45}$.

El fumus boni iuris es el juicio de verosimilitud acerca de la existencia del derecho que se reclama ${ }^{46}$.

Señala Romero que no se trata en ningún caso de la plena prueba del derecho o interés legítimo, sino que de una simple apariencia de la situación tutelada mediante el ejercicio de la acción, y siguiendo una antigua doctrina sentada por la Corte de Apelaciones de Santiago en 1904, esto se explica de la siguiente forma: "las medidas precautorias solo tienen por objeto responder a las resultas del juicio y no importan un prejuzgamiento de las cuestiones que en él se ventilan..." 47.

En lo que respecta al peligro en la demora, se refiere a la situación de peligro, cuya consumación se busca evitar concediendo la medida precautoria $^{48}$, y es un elemento de la esencia de toda medida cautelar, que deberá acreditar el peticionario, aportando los antecedentes de que disponga ${ }^{49}$.

Para Romero, la exigencia en la concurrencia de una situación de peligro evita los abusos en la concesión de las medidas, ya que al no existir dicho estado desaparece la necesidad de conceder la protección cautelar ${ }^{50}$.

El mismo artículo 24 de la Ley 20.600 dispone también que el Tribunal Ambiental podrá decretar medidas cautelares conservativas o innovativas, cuando tengan como fin resguardar un interés jurídicamente tutelado, teniendo en cuenta la verosimilitud de la pretensión invocada, o cuando sean necesarias para impedir los efectos negativos de los actos o conductas sometidos a su conocimiento.

El legislador ha exigido la concurrencia de estos requisitos cuando dispone que el requirente deberá acompañar los antecedentes que consti-

plazo de citación y se oponga a la medida.

Señala Romero Seguel, Alejandro (2007) Curso de Derecho Procesal Civil, T. I. Santiago: Editorial Jurídica de Chile, p. 58, que "No hemos incluido aquí la caución, ya que en nuestro derecho este requisito es eventual, exigiéndolo solo las medidas precautorias innominadas o las medidas prejudiciales precautorias (arts. 279 y 298 CPC)".

En este sentido, ArazI, Roland (1999) Medidas cautelares. Buenos Aires: Rubinzal-Culzoni, p. 7.

47 Romero (2007) 58, citando el fallo de la Corte de Apelaciones de Santiago, 27 de octubre de 1904, RDJ, t. II, sec. $2^{\text {a }}$, p. 68.

48 Una completa descripción de este elemento, Cortez Matcovich, Gonzalo (1999) "La configuración del periculum in mora en el régimen cautelar chileno". Revista de Derecho, Universidad de Concepción, $\mathrm{N}^{\circ}$ 205, enero-junio, pp. 99-114.

En la práctica se han presentado algunos problemas acerca de la carga de la prueba en el periculum in mora. Un examen puntual, con relación a la falta de garantías de la demandada, Tavolari Oliveros, Raúl (2000) "Facultades económicas de los litigantes y cautela judicial”. El proceso en acción. Valparaíso: Libromar, pp. 357-380. Romero (2007) 59. 
tuyan, a lo menos, presunción grave del derecho que se reclama o de los hechos denunciados, reiterando así la regulación ya contenida en el Código de Procedimiento Civil.

Donde sí establece una diferencia es en lo que respecta a la acreditación de estas exigencias, puesto que solo admite prueba documental, tanto para decretar la medida como para oponerse o solicitar el alzamiento de la misma, debiendo adjuntar el solicitante dicha prueba a las correspondientes solicitudes, para que el tribunal las coloque en conocimiento de la parte contraria, y citando luego a una audiencia dentro de un plazo no superior a diez días, en la que escuchará a las partes y resolverá sobre el futuro de la medida.

\section{(3.3.) LA CONFIGURACIÓN DEL PERICULUM IN MORA COMO CRITERIO FUNDAMENTAL PARA DECRETAR UNA MEDIDA CAUTELAR INNOVATIVA EN EL PROCEDIMIENTO MEDIO AMBIENTAL}

\section{(3.3.1.) Una aproximación al concepto de perjuicio irreparable}

Existe unanimidad en que lo cautelar obedece a una necesidad común que invoca como justificación, la necesidad de evitar el periculum in mora, el peligro en el retardo, y que genéricamente no es otra cosa que el riesgo constituido por el transcurso del tiempo necesario para la realización de la tutela.

El periculum in mora, que constituye la base de este presupuesto en las medidas cautelares, es conceptualizado por Calamandrei como la "existencia de un peligro de daño jurídico, derivado del retardo de una providencia jurisdiccional definitiva" 51 .

Tanto en las medidas conservativas como en las innovativas debe concurrir este requisito, pero con una configuración distinta según la función que desempeñe la correspondiente medida cautelar.

Siguiendo al maestro italiano, en ciertas ocasiones la medida tendrá por objeto asegurar bienes para la futura ejecución de la sentencia y en otras, se busca obtener de modo anticipado la satisfacción de la pretensión con el objeto de evitar un dańo irreparable.

Por lo anterior, el autor seńala que en el caso de las medidas precautorias conservativas, el periculum in mora se configura como un peligro en la tardanza derivada de la prosecución del litigio, y en que lo urgente "no es la satisfacción del derecho sino el aseguramiento preventivo de los medios aptos para determinar que la providencia principal, cuando llegue, sea justa y prácticamente eficaz" ${ }^{52}$, mientras que para el caso de las medidas innovativas, el periculum está constituido por la prolongación del

\footnotetext{
51 Calamandrei (2006) 42.

52 Calamandrei (2006) 71.
} 
estado de insatisfacción del derecho, recayendo la medida "directamente sobre la relación sustancial controvertida" 53 .

Como bien lo expresa Baracat, "para determinar el peligro en la demora hay que escudriñar la situación del demandado; en el daño irreparable hay que examinar la situación en que se encuentra el actor" 54

Agrega Calamandrei que "para aproximarse a una noción clara del periculum in mora es preciso dar otro paso: no basta que el interés en obrar nazca de un estado de peligro y que la providencia invocada por ello tenga la finalidad de prevenir un daño solamente temido, sino que es preciso, además, que a causa de la inminencia del peligro la providencia solicitada tenga carácter de urgencia en cuanto sea de prever que si la misma se demorase el daño temido se transformaría en daño efectivo" 55 .

Por ello, el peligro de un perjuicio irreparable implica la existencia de una situación que viene a aquejar al actor de forma tal "que se encuentre justificado otorgar algo o parte de la pretensión de mérito” 56 .

53 Calamandrei (2006) 72, lo que el autor denomina como "peligro de infructuosidad". La dogmática argentina, en la escuela iniciada especialmente por el profesor Jorge Peyrano, y siguiendo la interpretación jurisprudencial, han desdoblado este peligro en la demora, que clásicamente se ha señalado como uno de los presupuestos sustanciales de viabilidad de las medidas precautorias, llamando así al peligro que importe demorar la toma de una decisión que no admite dilaciones, para distinguirlo de otro peligro denominado "in damni", por el perjuicio irreparable que la omisión en adoptar la tutela jurisdiccional, pueda traer aparejada. En verdad, este recaudo no surge en forma expresa de norma alguna, pero sí de la posición que adoptó la Corte en los casos resueltos con esta suerte de anticipo de jurisdicción, cuando señala que el conocimiento del juez sobre los hechos que se le presentan debe ser mucho más cuidadoso, por las consecuencias que traerán aparejadas para el proceso. Esta mayor prudencia únicamente puede estar dirigida a apreciar con mayor claridad y precisión, tanto la verosimilitud del derecho, como el peligro de la demora, que bien pueden interpretarse como mayor certeza sobre el derecho invocado, y por otro lado, mayor evidencia del peligro en ciernes que se pretende evitar. Opina de modo contrario Palacio, Lino (1998) "La venerable antigüedad de la llamada medida cautelar innovativa y su alcance actual". Revista de Derecho Procesal, $\mathrm{N}^{\circ} 1$, agosto, pp. 105-112, quien ni siquiera cree necesario separar el periculum in mora del periculum in damni, puesto que este último se encontraría subsumido en el recaudo genérico del peligro en la demora, cubriendo este último todos los daños involucrados en el otorgamiento de la medida.

54 Baracat, Edgar (2009) "Reflexiones sobre la medida innovativa: su pasado y su futuro". En Peyrano, Jorge (Director): Medida Innovativa. Buenos Aires: Rubinzal-Culzoni, p. 60. En este mismo sentido, Peyrano, Jorge (2009) "La palpitante actualidad de la medida cautelar innovativa”. En Peyrano, Jorge (Director): Medida Innovativa. Buenos Aires: Rubinzal-Culzoni, pp. 19-42, pp. 19-20. Este criterio se mantuvo también en el emblemático fallo recaído en "Camacho Acosta, M. c/ Grafi Graf SRL", en que la Corte Suprema de Justicia de la Nación expresa en el considerando $n^{\circ} 5$ que "la tardanza en la colocación de la prótesis hasta el momento de la sentencia definitiva le provocará un perjuicio irreversible en la posibilidad de recuperación física y psíquica de parte...”.

55 Calamandrei (2006) 40.

56 Peyrano (2009) 33. Agrega el autor que comprobar que existe periculum in damni equivale a sostener que media "peligro de infructuosidad" en el proceso de que se trate, y en este sentido, su tesis sobre la configuración del periculum in mora coincide con la de Calamandrei. 
En base a lo anterior, la doctrina y la jurisprudencia se encuentran contestes en que la procedencia de la cautela innovativa se encuentra sujeta a la necesidad de evitar un perjuicio irreparable o un "peligro de infructuosidad", como lo denomina el citado autor italiano ${ }^{57}$, no siendo suficiente con un peligro en la tardanza, entendido este último como presupuesto propio de las medidas conservativas.

Para Peyrano esta clase de perjuicio "es el presupuesto propio y característico de la medida cautelar innovativa, consistente en que la situación (de hecho o derecho) que se pretende innovar ocasionaría (de subsistir) un daño irreparable al pretensor" ${ }^{28}$, confirmando esa tesis Arieta cuando señala que habría irreparabilidad "cuando los efectos del daño sobre el derecho son irreversibles" 59 .

Para acreditar la situación de peligro en este último caso, no basta el simple temor o aprensión de quien pide la medida innovativa, sino que debe tratarse de hechos apreciables objetivamente, debiendo el solicitante proceder a la demostración verosímil de estos requisitos que justifiquen efectivamente su otorgamiento, no bastando con la alegación de daños eventuales, sino que "será menester demostrar prima facie tales recaudos"60.

Nuestra jurisprudencia se ha hecho cargo de estos alcances en distintas sentencias pronunciadas en procedimientos medioambientales.

Así, se ha señalado por la Corte Suprema que "el carácter conservador que ostenta la potestad que ejercen los tribunales ordinarios de justicia en este tipo de arbitrio, en el entendido que por su conocimiento se resguarda y ampara la vigencia efectiva de los derechos precedentemente aludidos, con independencia de lo que pueda resolverse en

Calamandrei (2006) 70.

Peyrano (1981) 27.

Arieta, Giovanni (2011) I provvedimenti d'urgenza ex art. 700 C. P. C. Padova: Cedam, p. 130. De modo contrario opina Palacio (1998) 112, quien considera cuestionable que se condicione el otorgamiento de la medida a la concurrencia de este presupuesto, puesto que la exigencia es susceptible de ser limitada a connotaciones de carácter patrimonial. Agrega que en la forma como se ha configurado el periculum in mora en las medidas conservativas, es posible incorporar en dicho concepto una amplia gama de daños que permitiría ir más allá del perjuicio económico, extendiéndose también a daños físicos, morales y sicológicos. No concordamos con esta última posición. Creemos que tratándose de medidas cautelares innovativas, es dable la exigencia de requisitos más severos, puesto que el peligro en la demora en la cautela conservativa presenta una relación directa con el riesgo de insolvencia del demandado al momento en que se solicite la ejecución de la sentencia definitiva, mientras que la concesión de la medida cautelar innovativa no ha sido prevista como un aseguramiento del resultado de la acción, sino que más bien persigue un objetivo inmediato centrado en el solicitante, consistente en el agravamiento de su situación particular para el caso de no concederse tal medida.

60 La jurisprudencia argentina también ha asentado esta exigencia en distintos fallos, como por ejemplo "Flamini y otro con Asociación Bioquímica", Zeus 75-R-32, n 17.808 y "Laboratorios de Especialidades famaceúticas c/Inst. de Serv. Soc. para jubilados", interlocutorio 6921. 
otras instancias, obliga a adoptar las medidas que el restablecimiento del imperio del derecho exige cuando acciones $u$ omisiones arbitrarias o ilegales importen privación, perturbación o amenaza a su respecto. Sobre el particular, cabe precisar que a la fecha no hay garantía ni existe certeza de que la recurrida haya adoptado las medidas necesarias para que los hechos que la autoridad competente califica como "infracciones graves a la legislación ambiental" se hayan revertido, hechos que innegablemente a lo menos importan una amenaza a la garantía consagrada en el numero $8^{\circ}$ del articulo 19 de la Carta Fundamental, ya no tan sólo de la persona de los recurrentes sino que de toda esa comunidad, dadas las particularidades del caso de que se trata", agregando que lo anterior "hace procedente la adopción de las medidas necesarias para evitar el peligro de la magnitud aludida y constituye suficiente razón para hacer lugar al presente recurso de manera de proveer a la comunidad afectada de los resguardos que la situación exige y amerita, precisamente en protección de los derechos aludidos precedentemente" 61 , y agregando en fallo de fecha 6 de noviembre de 2014 que "conviene reiterar que la presente acción constituye una medida de tutela urgente de modo que, si en el curso de su substanciación se detectan riesgos o amenazas graves en relación a las garantías antes aludidas cuyo acaecimiento sea verosimil, corresponderá adoptar las medidas que se estimen conducentes para otorgar la debida protección"62.

En el mismo sentido se pronuncia la Corte de Apelaciones de Copiapó, cuando rechazando el recurso de protección ${ }^{63}$, señala que "dentro del contexto de la nueva institucionalidad ambiental, el recurso de protección reviste una acción de ultima ratio, por cuanto el legislador implementó una serie de acciones administrativas y judiciales, con medidas cautelares incluidas, para evaluar técnicamente las resoluciones de las Comisiones Regionales de Evaluación y para sancionar la implementación posterior de los proyectos. En efecto, para la primera evaluación de mérito técnico de las RCA se otorgó a todos los que hayan participado del periodo de evaluación el recurso de reclamación ante el Comité de Ministros con su correspondiente recurso al Tribunal Medio Ambiental correspondiente, y para los posibles riesgos o daños efectivos, se permite la denuncia la Superintendencia, la que incluye medidas

61 Sentencia dictada por la Tercera Sala de la Corte Suprema en la Causa rol n 9852/2013 de 9 de enero de 2014, caratulada "Marisol Ortega Aravena por sí y a nombre del Sindicato de Trabajadores Independientes Procesadoras de Prod. del Mar del Borde Costero Caleta Lo Rojas y otros contra Central Termoeléctrica Bocamina I Y II".

62 Sentencia dictada por la Tercera Sala de la Corte Suprema en la Causa rol no 15737/2014 (de 6 de noviembre de 2014, caratulada "Sindicatos Independientes de Trabajadoras Pescadoras y Recolectoras de Algas y Actividades Conexas de la Caleta lo Rojas y otros contra Empresa Endesa S.A”.

63 En sentencia dictada por la misma Corte de Apelaciones el 28 de abril de 2014, en autos Rol N436-2013 (El Morro III). 
cautelares desde el inicio del procedimiento de sanción", criterio que luego ratifica en sentencias posteriores ${ }^{64}$.

Por todo lo anterior, el órgano jurisdiccional está llamado a controlar con rigurosidad la existencia de esta condición, debiendo la verosimilitud del derecho "surgir de manera manifiesta de los elementos obrantes en la causa" ${ }^{\circ 5}$, puesto que la resolución implica la posibilidad de anticipar una tutela que luego resulte favorable.

\section{(3.3.2.) Alcances de la irreparabilidad del perjuicio}

Con la palabra perjuicio se ha querido hacer referencia a la lesión de derechos e intereses legítimos amparados por el ordenamiento, ya sea que se trate de daños al patrimonio o bien daños morales.

La irreparabilidad se trataría de un concepto que en palabras de la doctrina "se caracteriza por estar estrechamente vinculado con la afección o pérdida definitiva de derechos o facultades" 66 .

Ruzafa ${ }^{67}$ concreta de modo fáctico la exigencia de irreparabilidad, al considerar que la demora debe ser de entidad suficiente como para que influya en la sentencia o convierta su futura ejecución en ineficaz o imposible.

Como la medida tiene por objeto evitar que la lesión se siga produciendo mientras se alcanza la sentencia definitiva ${ }^{68}$, dicha lesión debe ser actual y de imposible o muy difícil reparación posterior.

La exigencia implica además detenerse en el análisis de la magnitud del perjuicio para que este pueda ser considerado como irreparable.

Se ha señalado también que en cuanto a la extensión del ámbito de la lesión, debe comprenderse dentro de este concepto no solamente el daño que nunca podrá ser reparado, sino también cualquier daño que resulte de muy difícil reparación o cuando la protección que le ha sido otorgada al derecho o interés sea insuficiente o tardía.

En lo que respecta a la lesión de derechos de carácter patrimonial, el criterio para considerar la imposibilidad en la reparabilidad del perjuicio

64 Causa no 124/2014 (Civil). Resolución no 6655, de Corte de Apelaciones de Copiapó, de 12 de junio de 2014, caratulada "Alvaro Varas del Canto con Comisión de Evaluación de la III Región de Atacama”.

65 Ruzafa, Beatriz (2009) "Notas sobre la medida innovativa y el daño irreparable". En Peyrano, Jorge (Director): Medida Innovativa. Buenos Aires: Rubinzal-Culzoni, pp. 343-344.

66 Bilesio, Juliana; Gasparini, Marisa (2009) "Medida innovativa: un cuarto presupuesto, el daño irreparable”. En Peyrano, Jorge (Director): Medida Innovativa. Buenos Aires: Rubinzal-Culzoni, p. 332. Hacen las autoras sinónimo a irreparable el que daño sea irremediable, insubsanable o irreversible.

67 Ruzafa, Beatriz (2009) "Notas sobre la medida innovativa y el daño irreparable". En Peyrano, Jorge (Director): Medida Innovativa. Buenos Aires: Rubinzal-Culzoni, p. 355.

Ruzafa (2009) 355. 
se determina en base a la capacidad económica del destinatario de la me$\operatorname{dida}^{69}$, y si puede hacer frente a una eventual indemnización por dańos y perjuicios $^{70}$.

En situaciones en que para decretar la irreparabilidad del perjuicio no se ha estado a criterio de carácter pecuniario, por tratarse de bienes extrapatrimoniales como la vida o la salud, el órgano jurisdiccional ha privilegiado los riesgos eventuales para el bien en peligro ${ }^{71}$.

Así por ejemplo, la jurisprudencia argentina, ha sostenido que "es procedente el dictado de una medida cautelar tendiente a la restitución del suministro de agua corriente y cloacas en la vivienda del actor, aun cuando este haya reconocido un crédito a favor de la empresa prestadora - en el caso, se suspendió el servicio por falta de pago-, pues se trata de un servicio público que provee un elemento vital para la subsistencia"72, y que "procede otorgar la medida cautelar innovativa que persigue obtener el registro provisional de un nombre de dominio en internet, pues al privar a la actora de usar su designación comercial en ese mercado... se lesiona su derecho de propiedad, al impedirsele comercializar desde alli sus productos" 73 .

También se ha declarado por la jurisprudencia comparada la procedencia de la cautela innovativa en materias relativas a la protección del medio ambiente y de contaminación acústica, en que se ha señalado que procede la medida solicitada, si la estridencia sonora afecta la calidad de vida del actor.

Otro aspecto a tener en cuenta es que la jurisprudencia ha vinculado el concepto de perjuicio irreparable al de "integridad del bien protegido", señalando que la irreparabilidad "no debe ser entendida solo con alcance patrimonial descartándosela como la mera invocación de posible reparación pecuniaria; porque, como lo ha puesto de manifiesto Guglielmo Saporito, irreparabilidad no es equiparable a no resarcibilidad, pues quien solicita la

69 Similar al criterio que se utiliza para determinar en el sistema anglosajón la procedencia de la injunction.

70 En este sentido "Bressan SA con Alvarez", Cam. Civ. y Com., Rosario, 25/06/98, que versaba sobre un juicio por desalojo en que la demandante solicitó como medida cautelar innovativa que se le restituyera una planta de acopio de cereales. El juez concedió la medida en atención a que el demandado se encontraba en manifiesto estado de insolvencia. Hasta aquí podría pensarse que un criterio de este tipo coincide más con un periculum in mora de tipo conservativo, pero el fallo agrega un requisito adicional, consistente en determinar si con la insolvencia del demandado se verían afectadas sus operaciones comerciales, lo que la resolución concluye de modo afirmativo.

71 En este punto, Berizonce, Roberto (2009) Tutelas procesales diferenciadas. Buenos Aires: Rubinzal-Culzoni, 2009.

72 En el juicio caratulado “Torre, Hugo M. c/D.J. con Aguas Argentinas S.A” (2001-2-602).

73 Dictamen pronunciado en el juicio caratulado BYK Argentina SA c/ Estado nacional (D.J. 2000-3-1094), relativo a la propiedad intelectual. 
tutela cautelar quiere que el bien tutelado permanezca integro, y no que se le asegure una indemnización"74.

Al solicitante de la medida por lo tanto no solo le corresponde la acreditación del peligro, sino que también su fundamentación ${ }^{75}$, de manera que el periculum in mora subyace a la solicitud como un presupuesto obvio, quedándole al juez la labor de determinar si la situación jurídica es o no cautelable.

Debe observarse además que parte de la jurisprudencia ha señalado que la medida cautelar innovativa resulta procedente cuando de su concesión no deriva un perjuicio mayor. En este caso se ha considerado que resultaría inconveniente su otorgamiento ${ }^{76}$.

Podemos concluir que la gravedad del perjuicio no depende de un pronóstico sobre la duración del proceso, y, así, de una evaluación en términos de extensión del tiempo necesario para alcanzar la sentencia; sino de la naturaleza y características objetivas de la situación antijurídica que se desea remover ${ }^{77}$, agregándose que habría irreparabilidad cuando los efectos del daño sobre el derecho son irreversibles.

\section{(3.3.3.) Excepcionalidad de la medida innovativa}

Para el caso en que debe procederse a la fijación de una medida cautelar innovativa, el legislador ha recogido la orientación jurisprudencial y dogmática mayoritaria que exige de modo particular la inminencia de un perjuicio irreparable como requisito necesario para su procedencia, lo que fija su marcado carácter excepcional y limita su ámbito de aplicación.

De esta forma, el artículo 24 en su inciso $6^{\circ}$ dispone que la cautela innovativa "solo podrá decretarse ante la inminencia de un perjuicio irreparable", redacción que permite concluir que su concurrencia es de carácter obligatorio, de tal manera que si el Tribunal considera que no concurren las circunstancias que la hagan procedente "podrá, de oficio, decretar otra medida cautelar que a su juicio corresponda", limitándose, creemos, al ámbito de las medidas cautelares conservativas.

La imposibilidad de obtener la protección solicitada por medio de otra medida precautoria, convierte a la medida cautelar innovativa en subsidiaria de las medidas típicas, agregándose por la doctrina que "solo debe decretarse si no existe otra medida precautoria que pueda cumplir

\footnotetext{
74 CSJ de Santa Fe, 4-5-97, "Malvicino c/Prov. de Santa Fe s/Inc. de suspensión de medida administrativa”.

75 En este sentido, Calderón Cuadrado, Pía (1992) Las medidas cautelares indeterminadas en el proceso civil. Madrid: Civitas, p. 174

76 En este sentido, CNCiv, 22-7-92, en los autos caratulados "Pesce Miguel c/Confederación Argentina de Judo", 1992, E-486.

77 Tommasseo (1983) 137-138.
} 
con la finalidad propuesta, y cuando la situación fáctica o jurídica ocasione una desigualdad intolerable para una de las partes o un daño que no pudiere ser reparado posteriormente" 78 .

Parte de la jurisprudencia también se ha orientado en este sentido, señalando que la medida cautelar innovativa debe constituir "el único camino viable a fin de asegurar la existencia del fin y objeto perseguido, y que cuando no resulta así por existir medidas menos perjudiciales que llevan a idénticos resultados, su improcedencia es manifiesta"79.

\section{(3.4.) Contracautela}

El artículo 24 inciso $3^{\circ}$ establece la posibilidad de que el Tribunal pueda exigir una caución al actor particular para responder de los perjuicios que podrían originarse, lo que en el caso de las medidas cautelares innovativas cobra especial importancia, ya que "viene a representar el necesario contrapeso de su despacho inaudita pars" 80 , y concretando de cierta manera el principio de igualdad procesal y el adecuado equilibrio entre las partes, en un procedimiento en que en principio de retarda la bilateralidad ${ }^{81}$.

La contracautela debe exigirse y constituirse antes de que se decrete la medida cautelar y como un requisito previo, debiendo el juez fijar su monto y naturaleza, teniendo en cuenta la urgencia de la medida y la verosimilitud del derecho que se invoca.

\section{(3.5.) PROVISIONALIDAd Y BILATERALIDAD EN LA CONCESIÓN DE LA MEDIDA}

Establece también este mismo artículo que las medidas decretadas son esencialmente provisionales, pudiendo modificarse, o dejarse sin efecto en cualquier estado de la causa.

La resolución que conceda o deniegue una medida cautelar se notificará al afectado, pudiendo llevarse a efecto sin esta diligencia siempre que existiere motivo grave para ello. En este caso, transcurridos cinco días sin

78 Giovannoni, Adrio (1980) "La medida cautelar innovativa dentro del ámbito de la tutela cautelar”. Libro de Actas y Ponencias, X Congreso Nacional de Derecho Procesal, Salta, p. 291.

79 CNCC Esp., 4/, 27-2-87, "Rossato c/ Tartaruca", Revista de Derecho Procesal n 1, p. 470.

80 Peyrano (2009) 27, y en concordancia con lo dispuesto por el artículo 24 inciso final, cuando señala que " siempre que existiere motivo grave, el tribunal podrá disponer que las medidas se lleven a efecto antes de notificar a la persona contra quien se dictan...”, debiendo notificarse en el plazo de 5 días desde que se concede.

81 En este sentido, Romero (2007) 66, citando a Calamandrei, Piero. "El proceso como un juego", en Estudios sobre el proceso civil. Buenos Aires: Ejea, p. 282, que "los límites que se deben reconocer en la concesión de medidas precautorias apuntan a evitar que ellas se conviertan en lo que Calamandrei describía, crudamente, como "un medio de coacción psicológica, un medio expeditivo, podría decirse, para agarrar al adversario por el cuello...”. 
que la notificación se efectúe, quedarán sin valor las diligencias practicadas. El Tribunal podrá ampliar este plazo por motivo fundado ${ }^{82}$.

\section{(3.6.) RÉGIMEN DE RECURSOS}

Si nos atenemos a lo dispuesto por el artículo 26 de la Ley 20.600, podemos concluir que la resolución que decreta una medida cautelar no es susceptible de recurso de apelación, ya que la procedencia de este último en el procedimiento medioambiental se ha restringido a resoluciones que declaren la inadmisibilidad de la demanda, las que reciban la causa a prueba y las que pongan término al proceso o hagan imposible su continuación.

Entendemos que en virtud de lo dispuesto por el artículo 47 de la citada ley, y haciendo una aplicación supletoria de las normas contenidas en el Código de Procedimiento Civil, debe siempre proceder el recurso de reposición, por cuanto tampoco se señala en la ley que estas resoluciones no sean susceptibles de recurso alguno.

\section{CONCLUSIONES}

1) Es una realidad que el tiempo obstaculiza el acceso a la justicia, existiendo consenso en la doctrina contemporánea de que el proceso debe constituir un instrumento que garantice de modo adecuado la tutela de los derechos subjetivos e intereses legítimos.

2) Surgen en la doctrina, la jurisprudencia y el Derecho comparado nuevas formas de tutela que permiten acceder a una justicia más rápida y eficaz.

3) Entre estas nuevas figuras destacan las nacidas en el seno de la tutela cautelar, como la medida innovativa, que sin perder su carácter de accesoria, permite anticipar en ciertas ocasiones, el contenido de la sentencia definitiva que se dictará posteriormente.

4) Abordar el concepto de lo cautelar implica repasar sus contenidos, y en especial los presupuestos para su procedencia, precisando las facultades de los jueces para otorgarlas en ciertas situaciones excepcionales

82 Norma idéntica a la ya contenida en el inciso $2^{\circ}$ del artículo 22 de la Ley 19.968, que dispone que "Las medidas cautelares podrán llevarse a efecto aun antes de notificarse a la persona contra quien se dicten, siempre que existan razones graves para ello y el tribunal asi lo ordene expresamente. Transcurridos cinco dias sin que la notificación se efectúe, quedarán sin valor las diligencias practicadas. El juez de familia podrá ampliar este plazo por motivos fundados". 
5) Para ello, el decreto de una medida cautelar innovativa requiere una configuración y una funcionalidad más exigente del periculum in mora, puesto que busca evitar un peligro de infructuosidad y no un peligro en la mera tardanza.

6) El peligro en la demora ofrece un ámbito relevante para su estudio, en cuanto a una perspectiva temporal del peligro que se intenta cautelar, y en cuanto al contenido de lo cautelado, referido al daño, actual o futuro; a la degradación de las cosas y en definitiva a la solvencia del demandado.

7) En la nueva institucionalidad medioambiental, la competencia para decretar medidas cautelares se radica en la Superintendencia del Medio Ambiente y en los tribunales ambientales.

8) Creemos que independientemente de cuál sea el órgano que decreta la medida cautelar innovativa, ellas son de carácter excepcional y de aplicación estricta, exigiéndose para su procedencia prueba que vaya más allá de antecedentes que puedan servir de presunción grave del derecho que se reclama, y resguardándose de modo adecuado los derechos de aquel contra quien se adoptan, con especial respeto por el principio de la bilateralidad.

\section{Bibliografía Citada}

Acosta Estévez, José (1995) Tutela procesal de los consumidores. Barcelona: Bosch.

Aguirrezabal Grünstein, Maite (2006) "Algunas precisiones en torno a los intereses supraindividuales: colectivos y difusos". Revista Chilena de Derecho, Vol. $33 \mathrm{~N}^{\circ} 1$.

Aguirrezabal Grünstein, Maite (2014) Defensa de los consumidores y acceso a la justicia. Un análisis del proceso colectivo en la legislación chilena. Santiago: Editorial LegalPublishing.

Aguirrezabal Grünstein, Maite (2014) "Algunas precisiones en torno a las medidas cautelares innovativas en el procedimiento por violencia intrafamiliar". Revista Chilena de Derecho Privado, $\mathrm{N}^{\circ} 21$.

ArazI, Roland (2005) "Procesos Urgentes". Justicia Argentina I.

Arazi, Roland (1999) Medidas cautelares. Buenos Aires: RubinzalCulzoni.

Arieta, Giovanni (2011) I provvedimenti d'urgenza ex art. 700 C. P. C. Padova: Cedam.

Balestro Faure, Miryam (2009) "La medida innovativa: ¡cuándo, cómo y para qué? En Peyrano, Jorge (Director): Medida Innovativa. Buenos Aires: Rubinzal-Culzoni.

Baptista Da Silva, Ovidio (1993) Teoría de la acción cautelar. Porto Alegre: Fabris Editor. 
BARACAT, Edgar (2009) "Reflexiones sobre la medida innovativa: su pasado y su futuro". En Peyrano, Jorge (Director): Medida Innovativa. Buenos Aires: Rubinzal-Culzoni.

Berizonce, Roberto (2003) "Presentación del libro La tutela de los derechos difusos, colectivos e individuales homogéneos”. En GIDI, Antonio y Ferrer Mac-Gregor, Eduardo (coordinadores): Hacia un Código Modelo para Iberoamérica. México: Editorial Porrúa.

Berizonce, Roberto (1996) "La tutela cautelar y la prestación jurisdiccional efectiva”. Revista Uruguaya de Derecho Procesal, N 1 .

Berizonce, Roberto (2009) Tutelas procesales diferenciadas, Buenos Aires: Rubinzal-Culzoni.

Bermúdez Soto, Jorge (2013) "Fundamento y límites de la potestad sancionadora administrativa en materia ambiental". Revista de Derecho de la Pontificia Universidad Católica de Valparaíso, $\mathrm{N}^{\circ} 40$, pp. 421-447.

Bertelsen Repetto, Raúl (1998) “El recurso de protección y el derecho a vivir en un medio ambiente libre de contaminación. Examen de quince años de jurisprudencia”. Revista Chilena de Derecho, Vol. 25.

Bilesio, Juliana; Gasparini, Marisa (2009) "Medida innovativa: un cuarto presupuesto, el daño irreparable”. En Peyrano, Jorge (Director): Medida Innovativa. Buenos Aires: Rubinzal-Culzoni.

Bordalí Salamanca, Andrés (2004) La tutela jurisdiccional del medio ambiente. Santiago: Editorial Fallos del Mes.

Bordalí Salamanca, Andrés (1998) “Titularidad y legitimación activa sobre el ambiente en el Derecho chileno". Revista de Derecho de la Universidad Austral de Chile, Vol. IX, diciembre de 1998.

Bordali Salamanca, Andrés (2006) "El recurso de protección entre exigencias de urgencia y seguridad jurídica". Revista de Derecho de la Universidad Austral de Chile, diciembre, Vol. 19, № 2.

Calamandrei, Piero (2006) Introducción al Estudio Sistemático de las Medidas Cautelares. Lima: Ara Ediciones.

Calamandrei, Piero (1945) "El proceso como un juego", en Estudios sobre el proceso civil. Buenos Aires: Ejea.

Calderón Cuadrado, Pía (1992) Las medidas cautelares indeterminadas en el proceso civil. Madrid: Civitas.

Cappelletti, Mauro (1995) "Formaciones sociales e intereses de grupo frente a la justicia civil". Boletín Mexicano de Derecho Comparado, $\mathrm{N}^{\circ}$ 83.

Carbone, Carlos (2009) "Esquicio diferenciador entre la medida cautelar innovativa y el despacho interino de fondo". En Peyrano, Jorge (Director): Medida Innovativa. Buenos Aires: Rubinzal-Culzoni.

Carnellutti, Francisco (1944) Sistema de Derecho Procesal Civil, trad. Alcalá-Zamora. Buenos Aires: UTEHA. 
Comoglio, Luigi; Ferri, Corrado (1990) "La tutela cautelare in Italia". Rivista di Diritto Processuale. Padova: Cedam T. XLV.

Cortez Matcovich, Gonzalo (1999) "La configuración del periculum in mora en el régimen cautelar chileno". Revista de Derecho, Universidad de Concepción, $\mathrm{N}^{\circ} 205$, enero-junio.

De Los SAntos, Mabel (1995) "La medida cautelar innovativa y el anticipo de la sentencia. Su ubicación en los llamados procesos urgentes". Revista Uruguaya de Derecho Procesal, N² .

FÁbrega，Jorge.; Arjona Adán (1989) “Medidas cautelares innominadas". Revista del Instituto Colombiano de Derecho Procesal, Vol. II, $\mathrm{N}^{\circ} 8$.

Garrote, Angel (1997) "La tutela judicial anticipada. Las medidas de satisfacción anticipada y las medidas autosatisfactivas". Libro de Ponencias del XIX Congreso Nacional de Derecho Procesal, Corrientes, 6 al 8 de agosto de 1997.

Gascón Inchausti, Fernando (1998) Medidas cautelares de proceso civil extranjero. Granada: Comares.

Giovannoni, Adrio (1980) "La medida cautelar innovativa dentro del ámbito de la tutela cautelar". Libro de Actas y Ponencias, X Congreso Nacional de Derecho Procesal, Salta, 1980.

Gutiérrez De Cabiedes, Pablo (1998) La tutela jurisdiccional de los intereses supraindividuales; colectivos y difusos. Navarra: Aranzadi.

López Simó, Francisco (2001) Las condenas de futuro: (Su régimen en la Ley 1/2000, de Enjuiciamiento Civil). Navarra: Aranzadi.

Marín González, Juan Carlos (2004) Las medidas cautelares en el proceso civil chileno. Santiago: Editorial Jurídica de Chile.

Marín, Juan Carlos (2003) "Referencia a la tutela cautelar en el derecho inglés". Revista de Derecho de la Universidad de Valdivia, Vol.15.

MARINONI, Luis (2010) "La tutela anticipatoria en la reforma del proceso civil brasileño". Justicia Santafesina, N² 25.

Menéndez, Patricia (2009) "La medida innovativa como herramienta para afianzar la justicia”. En Peyrano, Jorge (Director): Medida Innovativa. Buenos Aires: Rubinzal-Culzoni.

Minvielle, Bernardette (1995) "La problemática de la medida cautelar innovativa”. Revista Uruguaya de Derecho Procesal, N².

Morello, Augusto (1998) Estudios de derecho procesal: nuevas demandas, nuevas respuestas. Buenos Aires: Abeledo-Perrot.

Moscoso Restovic, Pía (2011) "Principios de competencia judicial internacional y de protección del medio ambiente". Ius et Praxis, Vol. $17, \mathrm{~N}^{\circ} 2$, pp. $283-304$

Palomo Vélez, Diego (2003) “Tutela del medio ambiente: abandono del paradigma de la litis individual". Revista de Derecho, (Universidad Austral de Chile), Vol. XIV. 
Palacio, Lino (1998) "La venerable antigüedad de la llamada medida cautelar innovativa y su alcance actual”. Revista de Derecho Procesal, $\mathrm{N}^{\circ} 1$.

Peyrano, Jorge (2009) "La batalla por la medida cautelar innovativa". En Peyrano, Jorge (Director): Medida Innovativa. Buenos Aires: Rubinzal-Culzoni.

Peyrano, Jorge (1998) "Régimen de las medidas autosatisfactivas. Nuevas propuestas". La Ley, 1998-A-968.

Peyrano, Jorge (2009) "La medida cautelar innovativa: una realidad, una esperanza”. En Peyrano, Jorge (Director): Medida Innovativa. Buenos Aires: Rubinzal-Culzoni.

Peyrano, Jorge (1981) Medida Cautelar Innovativa. Buenos Aires: Depalma.

Peyrano, Jorge (2009). "La palpitante actualidad de de la medida cautelar innovativa". En Peyrano, Jorge (Director): Medida Innovativa. Buenos Aires: Rubinzal-Culzoni.

Ramos Méndez, Francisco (1985) "Las medidas cautelares indeterminadas". Justicia $85, \mathrm{~N}^{\circ}$ I.

Romero Seguel, Alejandro (2007) Curso de Derecho Procesal Civil, T. I. Santiago: Editorial Jurídica de Chile.

Ruzafa, Beatriz (2009) "Notas sobre la medida innovativa y el daño irreparable". En Peyrano, Jorge (Director): Medida Innovativa. Buenos Aires: Rubinzal-Culzoni.

Ruzafa, Beatriz (2009) "Notas sobre la medida innovativa y el daño irreparable". En Peyrano, Jorge (Director): Medida Innovativa. Buenos Aires: Rubinzal-Culzoni.

Urdaneta Sandoval, Carlos (1998) "Introducción al análisis sistemático de las medidas cautelares atípicas del Código de Procedimiento Civil Venezolano". Revista de Derecho, $\mathrm{N}^{\circ} 59$.

VASAK, Karel (1982) "Human rights: as a legal reality". The international dimensions of human rights. Connecticut: Greenwood Press.

Vescovi, Enrique (1996) "La búsqueda de una mayor eficacia para la justicia. Ejecución. Tutela anticipada y otras medidas en el Derecho comparado". Revista Uruguaya de Derecho Procesal, N 3.

Tommasseo, Ferrucio (1983) I provvedimenti d'urgenza (Strutura e limite della tutela anticipatoria). Padova: Cedam. 